\title{
Erratum to: Layer-by-Layer Analysis of the Stress-Strain State of Three-Layer Shells with Cutouts
}

\author{
V. N. Bakulin ${ }^{1 *}$ \\ ${ }^{1}$ Institute of Applied Mechanics of the Russian Academy of Sciences, \\ Leningradskii pr. 7, Moscow, 125040 Russia \\ Received October 5, 2017; revised October 5, 2017; accepted February 28, 2018
}

DOI: $10.3103 / \mathrm{S} 002565441906013 \mathrm{X}$

There was a mistake in the affiliations. The right affiliation is "Institute of Applied Mechanics of the Russian Academy of Sciences, Leningradskii pr. 7, Moscow, 125040 Russia."

The original article can be found online at https://doi.org/10.3103/S0025654419020092.

*e-mail: vbak@yandex.ru 